\title{
Study on Typhoon Characteristic Based on Bridge Health Monitoring System
}

\author{
Xu Wang, ${ }^{1}$ Bin Chen, ${ }^{2}$ Dezhang Sun, ${ }^{3}$ and Yinqiang $\mathrm{Wu}^{4}$ \\ ${ }^{1}$ State Key Laboratory Breeding Base of Mountain Bridge and Tunnel Engineering, Chongqing Jiaotong University, \\ Chongqing 400074, China \\ ${ }^{2}$ College of Civil Engineering and Architecture, Zhejiang University, Hangzhou 310058, China \\ ${ }^{3}$ Institute of Engineering Mechanics, China Earthquake Administration, Harbin 150080, China \\ ${ }^{4}$ Bureau of Public Works of Shenzhen Municipality, Shenzhen 518006, China
}

Correspondence should be addressed to Dezhang Sun; sundz2008@163.com

Received 25 March 2014; Revised 8 May 2014; Accepted 8 May 2014; Published 10 June 2014

Academic Editor: Ying Lei

Copyright (C) $2014 \mathrm{Xu}$ Wang et al. This is an open access article distributed under the Creative Commons Attribution License, which permits unrestricted use, distribution, and reproduction in any medium, provided the original work is properly cited.

Through the wind velocity and direction monitoring system installed on Jiubao Bridge of Qiantang River, Hangzhou city, Zhejiang province, China, a full range of wind velocity and direction data was collected during typhoon HAIKUI in 2012. Based on these data, it was found that, at higher observed elevation, turbulence intensity is lower, and the variation tendency of longitudinal and lateral turbulence intensities with mean wind speeds is basically the same. Gust factor goes higher with increasing mean wind speed, and the change rate obviously decreases as wind speed goes down and an inconspicuous increase occurs when wind speed is high. The change of peak factor is inconspicuous with increasing time and mean wind speed. The probability density function (PDF) of fluctuating wind speed follows Gaussian distribution. Turbulence integral scale increases with mean wind speed, and its PDF does not follow Gaussian distribution. The power spectrum of observation fluctuating velocity is in accordance with Von Karman spectrum.

\section{Introduction}

Typhoon disaster is a major disaster in China, which has caused serious property and casualty losses annually and threatened sustainable development along the east coast of China. To have a better understanding of bridge destruction reasons from typhoon, wind characteristics near ground during typhoon attack must be studied firstly. However, experimental simulation of typhoon is very difficult because of its particularity. This has led to field measurement that has been recognized as the most effective research method and long-term direction in wind-resistant research of structure [1]. A huge mass of data was accumulated and parts of research result had been used in model of conduct in developed countries, where the field-measured research in strong wind characteristics developed earlier. Database for wind characteristics had been built in some countries, where the research of wind engineering is developed [2-6]. China's field-measured research of wind characteristics developed later but very fast; some valuable research results had been achieved in recent years [7-12]. Currently, most researches on near ground wind characteristics during typhoon attack focus on buildings; few have been performed on bridges, but it is important for wind engineering research.

In China, health monitoring systems have been installed on many long span bridges [13-16] to capture health states of bridges. Among all these systems, the health monitoring of wind load is of primary importance to bridge health monitoring systems because the health monitoring information gathered could be used in bridge design and construction. However, current practices of strong wind characteristics using wind load monitoring system on bridge site are still encountering shortage.

Based on the wind data measured from the anemometer positioned on Jiubao Bridge at $6 \mathrm{~m}$ height, Hangzhou city, near-ground wind characteristics under typhoon HAIKUI in 


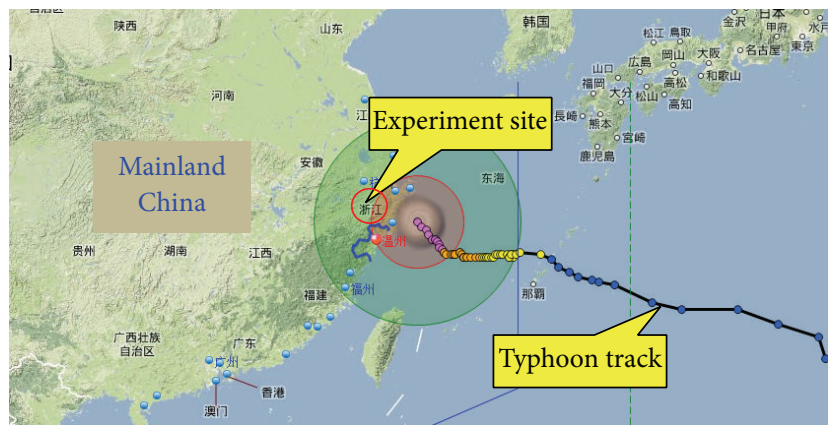

FIgURE 1: Experiment site and track of typhoon HAIKUI.

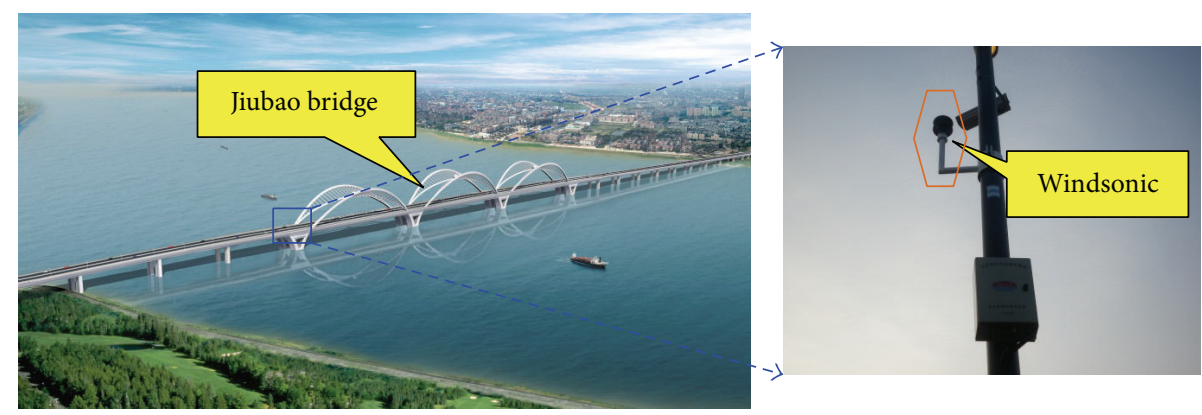

FIgURE 2: The location and photo of anemometers.

2012 were discussed in this paper, which include wind speed and direction, gust factor, turbulence intensity, peak factor, turbulence integral scale, and power spectrum of wind speed. Obviously, such studies are useful for promotions of windresistant design of bridge in the future.

\section{Site Description and Measurement Characterization}

2.1. Introduction of Typhoon HAIKUI. In 2012, the 11th tropical storm "HAIKUI" (named by HAIKUI, number 1211 tropical cyclone), named from a Chinese marine animal, headed to the coast of East China Sea at 17:00 on August 17, 2012, and landed at Zhejiang province in the morning of August 8. The location of the eye was $640 \mathrm{~km}$ from southwest of Zhejiang province, which was very close to the test bridge. The maximum 10 min mean wind speed at $10 \mathrm{~m}$ height was found to be $28 \mathrm{~m} / \mathrm{s}$, and the lowest pressure was $980 \mathrm{hPa}$. Figure 1 shows a satellite view of the path of typhoon HAIKUI and the experiment site. According to the statistical results of meteorological data from Chinese Ministry of Civil Affairs and Disaster Reduction Office, typhoon HAIKUI caused 6 casualties in Zhejiang, Shanghai, Jiangsu, and Anhui provinces and forced 2.173 million people to evacuate. The most damaged area was Zhejiang province, resulting in 7.001 million people involved, 1.546 million people were forced to move in emergency, and almost 5100 houses were destroyed.

Jiubao Bridge was located on Qiantang River, Hangzhou. The construction work began on December 18, 2009, and was completed in 2012. The bridge was designed to a standard bidirectional and six traffic lanes freeway, combining with
$80 \mathrm{~km} / \mathrm{h}$ of speed limit and about 1855 meters in span length. The whole bridge health monitoring systems which were comprised of vehicle system, wind speed and direction measurement system, and fatigue detection system were installed and distributed on the bridge. The meteorological data of typhoon was detected by a two-dimensional sonic anemometer in the wind speed and direction measurement system (see Figure 2). The anemometer, produced by British Gill Company, was Windsonic and has a sampling frequency of $4 \mathrm{~Hz}$. Wind direction was defined north as $0^{\circ}$ along a clockwise direction varying from $0^{\circ}$ to $360^{\circ}$. Specifications and parameters of anemometer were considered with the records indicated in Table 1.

\section{Study of the Field-Measured Wind Data}

3.1. Mean Wind Speeds and Wind Directions. Figures 3 and 4 show the time history of wind speeds and directions of typhoon HAIKUI from 0:00 on August 8, 2012, to 0:00 August 9, 2012. Because typhoon HAIKUI did not directly impact the experimental site in lateral direction, an uphill and a downhill of wind speed were observed in the time history, indicating that a peak value was recorded.

Before analyzing wind characteristics, the overall sample needs to be separated into several segments by a specified time interval. They are different from regulations of time interval of mean wind speed among standards in many countries, such as $3 \mathrm{~s}$ used in America [17] and India [18] and 10 min used in Japan [19], Europe [20], and China [21]. In this paper, according to Chinese standard, wind data was separated into 144 samples, and the maximum 10 min mean 
TABLE 1: Specifications of anemometer.

\begin{tabular}{|c|c|c|c|c|c|c|}
\hline \multirow[t]{2}{*}{ Brand (type) } & \multicolumn{2}{|r|}{ Wind speed } & \multicolumn{2}{|c|}{ Wind direction } & \multicolumn{2}{|c|}{ Measurement and structure } \\
\hline & Range & 0-60 m/s (116 Knots) & Range & $0-359^{\circ}$ & Frequency & $\begin{array}{c}0.25 \mathrm{~Hz}, 0.5 \mathrm{~Hz}, 1 \mathrm{~Hz}, 2 \mathrm{~Hz} \\
\text { or } 4 \mathrm{~Hz}\end{array}$ \\
\hline \multirow{4}{*}{$\begin{array}{l}\text { Gill } \\
\text { Windsonic }\end{array}$} & Accuracy & $\pm 2 \% ; 12 \mathrm{~m} / \mathrm{s}$ & Accuracy & $\pm 3^{\circ}$ at $12 \mathrm{~m} / \mathrm{s}$ & Parameter & $\mathrm{U}$ and $\mathrm{V}$ \\
\hline & Resolution & $0.01 \mathrm{~m} / \mathrm{s}(0.02$ Knots $)$ & Resolution & $1^{\circ}$ & $\begin{array}{l}\text { Measurement } \\
\text { unit }\end{array}$ & $\begin{array}{l}\mathrm{m} / \mathrm{s}, \mathrm{knots}, \mathrm{mph}, \mathrm{kph}, \\
\mathrm{ft} / \mathrm{min}\end{array}$ \\
\hline & $\begin{array}{l}\text { Reaction } \\
\text { time }\end{array}$ & $0.25 \mathrm{~s}$ & $\begin{array}{l}\text { Reaction } \\
\text { time }\end{array}$ & $0.25 \mathrm{~s}$ & Size & $142 \mathrm{~mm} \times 160 \mathrm{~mm}$ \\
\hline & Lowest & $0.01 \mathrm{~m} / \mathrm{s}$ & l & l & Wight & $0.5 \mathrm{Kg}$ \\
\hline
\end{tabular}

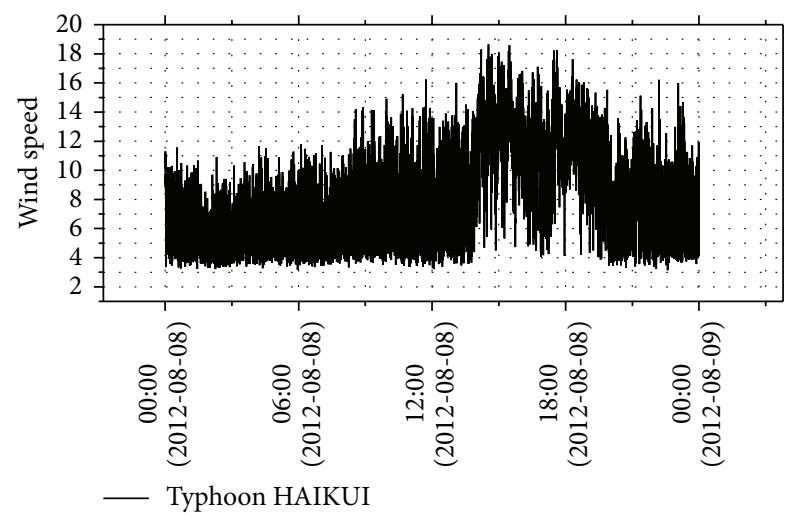

FIGURE 3: Instantaneous wind speed during typhoon HAIKUI.

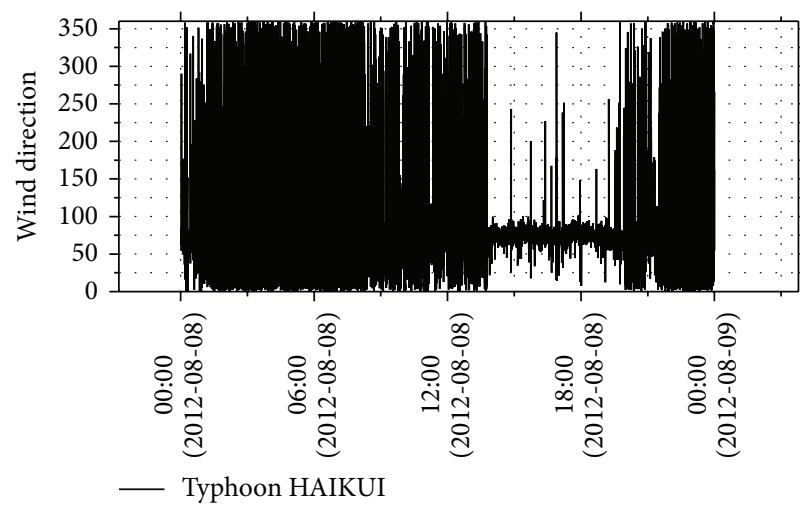

FIGURE 4: Instantaneous wind direction during typhoon HAIKUI.

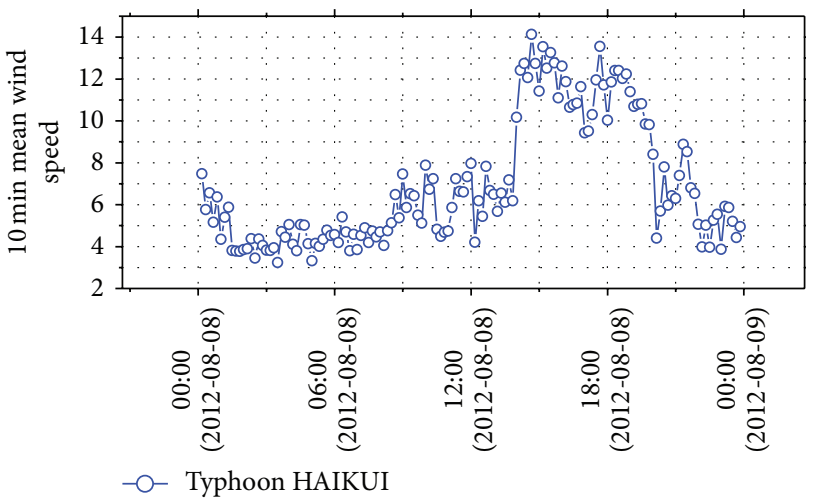

Figure 5: 10 min mean wind speed during typhoon HAIKUI.

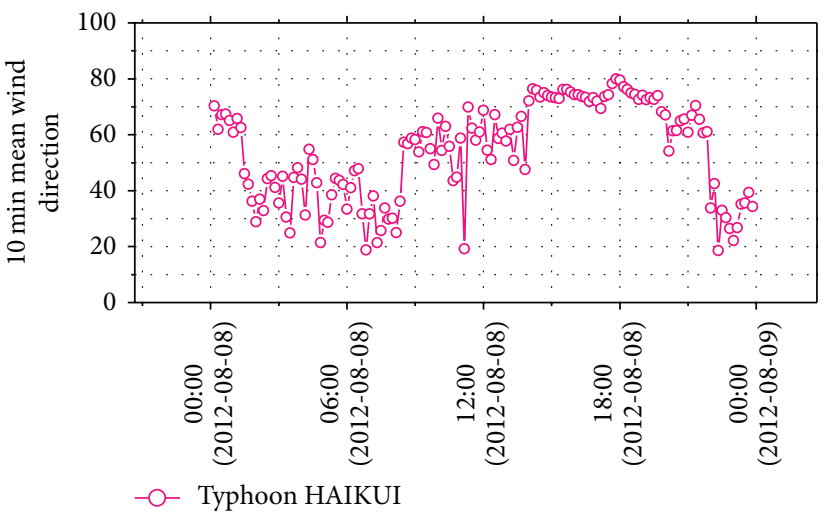

FIGURE 6: 10 min mean wind direction during typhoon HAIKUI.

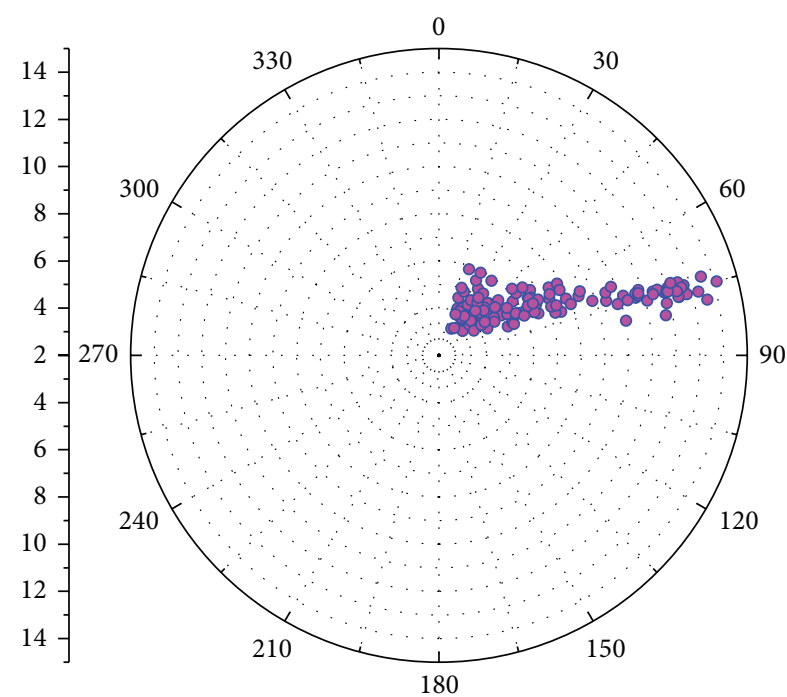

- Mean wind speed

Figure 7: 10 min mean wind speed versus mean wind direction.

wind speed was $14.12 \mathrm{~m} / \mathrm{s}$. Figures 5 and 6 show time histories of 10 min mean wind speed and horizontal wind direction. Variations of 10 min mean wind speed with horizontal wind direction were shown in Figure 7, which made the variation trend of mean wind speed with horizontal wind direction intuitive. 
After breaking down to 10 min time interval, the wind speed vector was resolved into three components [22], two of which are orthogonal, namely, $u_{x}(t)$ and $u_{y}(t)$, and can be measured synchronously by a two-dimensional sonic anemometer, denoting directions on $x$-axis and $y$-axis, respectively. The horizontal wind speed $U$ and main wind direction $\phi$ are calculated by the following formulas:

$$
\begin{aligned}
& U=\sqrt{{\overline{u_{x}(t)}}^{2}+{\overline{u_{y}(t)}}^{2}}, \\
& \cos (\phi)=\frac{\overline{u_{x}(t)}}{U}, \quad \sin (\phi)=\frac{\overline{u_{y}(t)}}{U}, \\
& \phi=\arccos \frac{\overline{u_{x}(t)}}{U}+\operatorname{step}\left(-\overline{u_{y}(t)}\right) \cdot 180^{\circ},
\end{aligned}
$$

where $\operatorname{step}(\cdot)$ is step function, $\overline{u_{x}(t)}$ is the mean wind speed in 10 min time interval along $X$-direction, and $\overline{u_{y}(t)}$ has the same meaning along $Y$-direction.

The longitudinal fluctuating wind speed $u(t)$ and lateral fluctuating wind speed $v(t)$ are obtained from

$$
\begin{aligned}
& u(t)=u_{x}(t) \cos \phi(t)+u_{y}(t) \sin \phi(t)-U, \\
& v(t)=-u_{x}(t) \sin \phi(t)+u_{y}(t) \cos \phi(t) .
\end{aligned}
$$

3.2. Turbulence Intensity. Turbulence intensity is considered the relative index for intensity of turbulence and then determined as

$$
I_{i}=\frac{\sigma_{i}}{U} \quad(i=u, v, w)
$$

where $\sigma_{i}$ is the standard deviation of fluctuating wind speed for component $i(i=u, v, w)$.

Similar diurnal patterns of $10 \mathrm{~min}$ fluctuating wind speed distribution are shown in longitudinal (Figure 8(a)) and lateral (Figure 8(b)) directions. The changes in turbulence intensities are slow between 00:00 and 12:00 on August 8, with average turbulence intensities being 0.47 and 0.40 and maximum values being 0.71 and 0.67 in longitudinal and lateral directions, respectively. In both directions, a sharp decrease is found in the period between 12:00 and 20:00 (the lowest average intensities being 0.16 and 0.13 , resp.) before an increase in the period between 20:00 and 00:00 on August 9 (variation ranging from 0.1 to 0.7 ).

Figure 9 shows both longitudinal and lateral turbulence intensity as a function of $10 \mathrm{~min}$ mean wind speed. The overall turbulence intensities reduce with decreased mean wind speed. It is clear from Figure 9 that an obvious decrease is found in turbulence intensities before mean wind speed approaching $8 \mathrm{~m} / \mathrm{s}$, but the changes become small when mean wind speed is greater than $8 \mathrm{~m} / \mathrm{s}$.

Table 2 shows the ratio of average longitudinal turbulence intensity to average lateral turbulence intensity in both domestic and international field research results. It can be seen from Table 2 that the ratio of the case is slightly larger than that in Peng et al. [12] and Fu et al.'s [23] results but quite close to the results from normal storm wind and typhoon by Li et al. [9], Cao et al. [6], and Shiau and Chen [24-26].
3.3. Gust Factor. Gust factor is defined as the ratio of maximum gust wind speed over average gust wind speed. It can be expressed as

$$
\begin{aligned}
G_{u}(t) & =1+\frac{\max (\overline{u(t)})}{U}, \\
G_{v}(t) & =\frac{\max (\overline{v(t)})}{U},
\end{aligned}
$$

where $\max (\overline{u(t)})$ and $\max (\overline{v(t)})$ are the maximum gust wind speed in the period of $t$ for longitudinal and lateral fluctuates, respectively.

Figure 10 shows the distribution of $3 \mathrm{~s}$ gust factor as a function of $10 \mathrm{~min}$ mean wind speed both in longitudinal (Figure 10(a)) and lateral (Figure 10(b)) directions. An obvious decrease of gust factor under low wind speed can be seen, but the rate of reduction goes smaller when wind speed becomes high. The average ratio of longitudinal gust factor to lateral gust factor is 0.30 .

3.4. Peak Factor. There is a similarity in the definition of peak factor as of gust factor. The following expression for peak factor which describes the intensity of fluctuating wind speed is employed:

$$
g_{u}=\frac{\widehat{U}_{t}-U}{\sigma_{u}},
$$

where $\widehat{U}_{t}$ is the maximum value of $t$ min average wind speed of the longitudinal component of fluctuating wind velocity record and $\sigma_{u}$ is the corresponding standard deviation.

The quantity of peak factor was determined from the three-second averages, shown as a function of time during a one-day period coincident with the passage of typhoon HAIKUI (Figure 11) and 10 min mean wind speed (Figure 12). In each figure, the distribution of the data is in the range of 0.6 and 2.5; the average and standard deviations are 1.52 and 0.34 , respectively. A noticeable decrease was found from the analysis of the average peak factor compared with Huang's results [12].

3.5. Probability Density Distribution. The probability density function of wind speed fluctuations is customarily with Gauss hypothesis. However, a similar statistical description of the wind speed fluctuations is generally the lack of certainty when applied to strong typhoon. Analysis of the wind speed fluctuations in longitudinal (Figure 13) and lateral (Figure 14) directions confirms a fairly good agreement with a Gaussian distribution through moment estimation method. It is believed the wind speed fluctuations are examined as Gaussian processes in this region of wind speed.

3.6. Turbulence Integral Scale. Turbulence is a three-dimensional spatial structure, and its nine parameters correspond to fluctuating wind speeds in longitudinal $u$, lateral $v$, and vertical $w$ directional components. For example, $L_{u}^{x}, L_{u}^{y}$, and $L_{u}^{z}$ are the average integral scales of longitudinal-dependent 


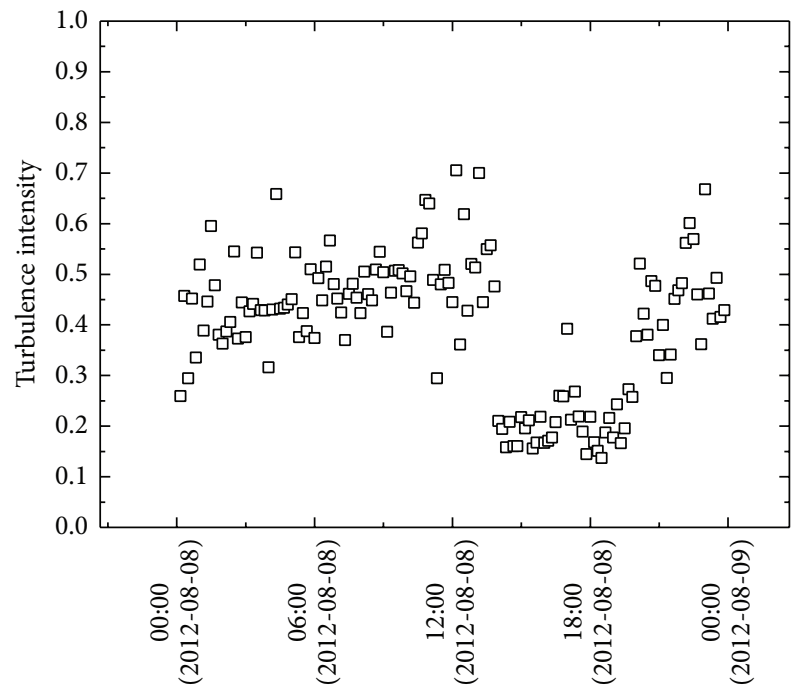

๑ Longitudinal

(a) Longitudinal

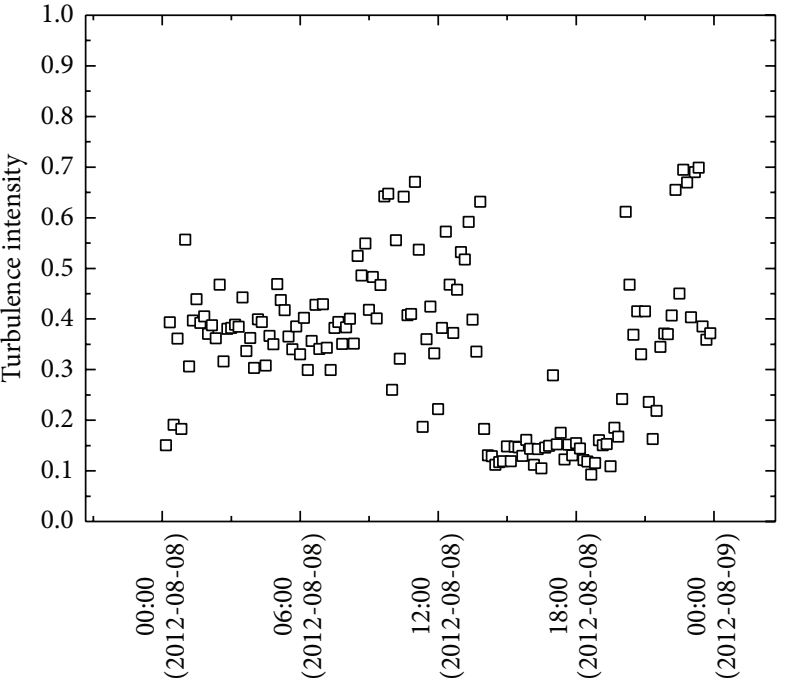

$\square$ Lateral

(b) Lateral

FIGURE 8: Variation of turbulence intensity during typhoon HAIKUI.

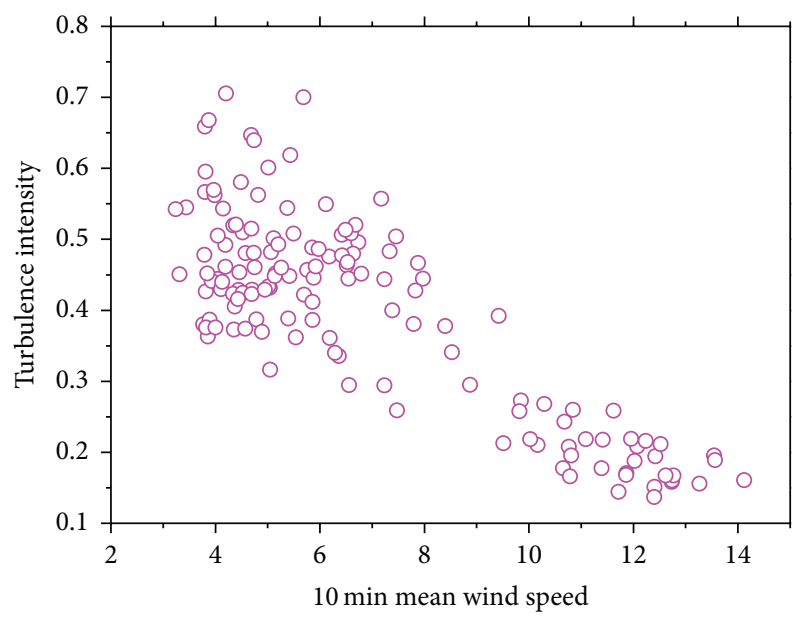

○ Longitudinal

(a) Longitudinal

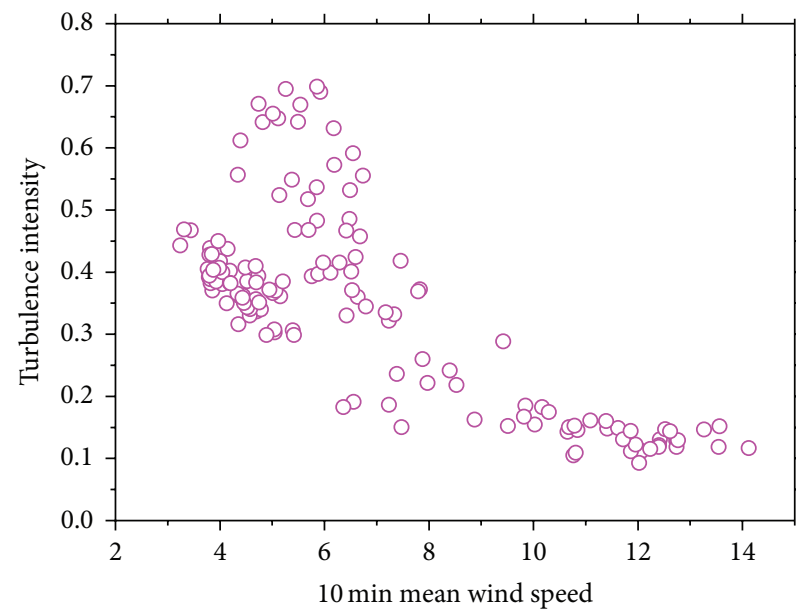

○ Lateral

FIgURE 9: Variation of turbulence intensities with wind speed.

TABLE 2: Ratios of turbulence intensity among the turbulence components.

\begin{tabular}{lcccc}
\hline Research man & Wind & Height (m) & $I_{u}: I_{v}$ & Sites \\
\hline Tieleman [27] & Normal strong wind & 5 & $1: 0.80$ & Holland \\
\hline Cao et al. [6] & Typhoon Maemi & 10 & $1: 0.83$ & $1: 0.98$ \\
\hline \multirow{2}{*}{ Shiau } & Typhoon Zeb [24] & & $1: 0.78$ & $1: 0.78$ \\
& Typhoon Babs [25] & 26 & $1: 0.7$ & Tapan \\
\hline Fu et al. (2008) [23] & Typhal strong wind [26] & & $1: 0.66$ & Guangzhou, China \\
\hline & & 10 & $1: 0.65$ & Shanghai, China \\
Peng et al. [12] & Typhoon Muifa & 10 & $1: 0.74$ & Hangzhou, China \\
& & 20 & $1: 0.85$ &
\end{tabular}




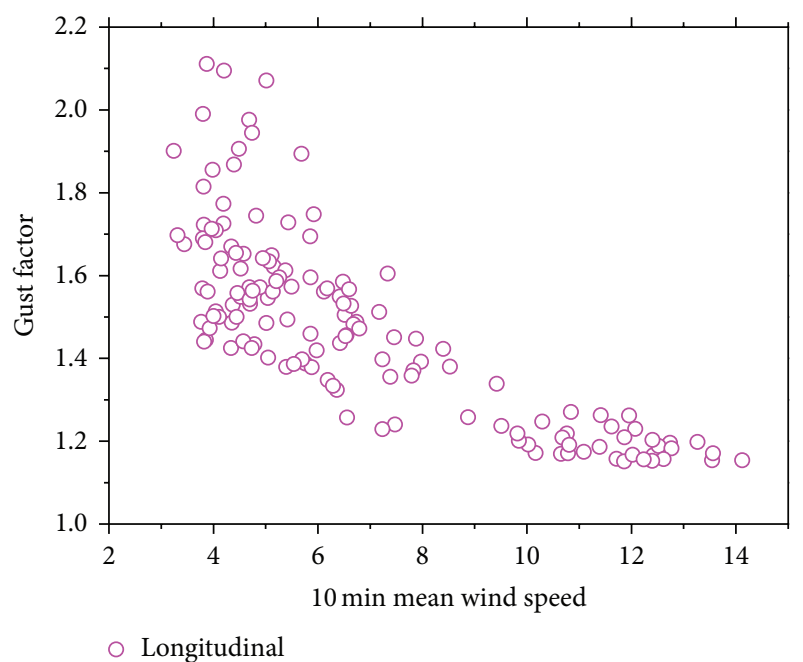

(a) Longitudinal

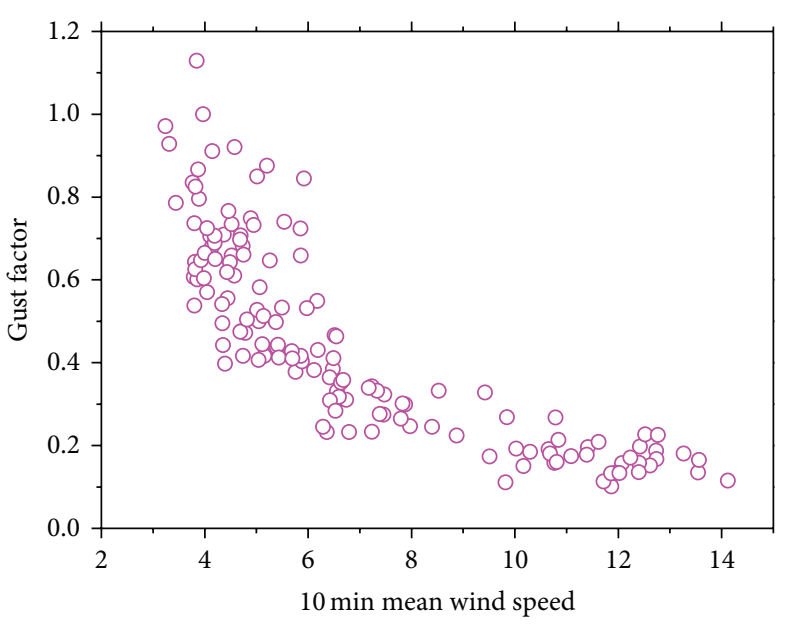

○ Lateral

FIGURE 10: Variation of gust factors with wind speed.

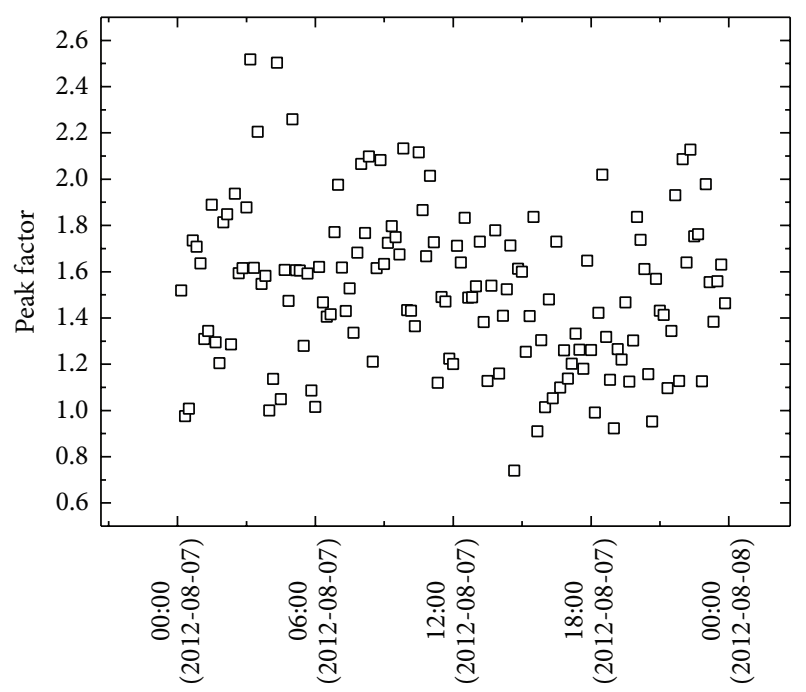

口 Peak factor

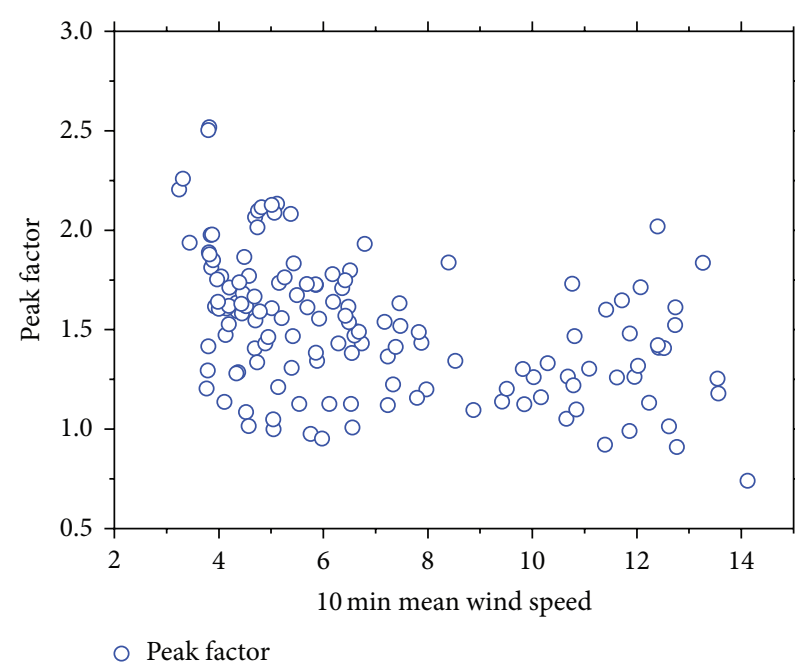

FIGURE 12: Variation of peak factor with wind speed.

be calculated by autocorrelation function integral method depending on Taylor hypothesis and interpreted as

$$
L_{i}^{x}=\frac{U}{\sigma_{i}^{2}} \int_{0}^{\alpha} R(\tau) d \tau, \quad i=u, v, w,
$$

where $R(\tau)$ is the autocorrelation function and $\alpha$ is the variable when autocorrelation coefficient drops to 0.05 [4].

In Figure 15, turbulence integral scales of longitudinal and lateral components determined from $10 \mathrm{~min}$ average show a clear dependency on 10 min mean wind speed, and increasing quantity is recorded by increased 10 min mean wind speed. For 10 min mean wind speed is greater than $8 \mathrm{~m} / \mathrm{s}$, turbulence integral scales drastically change and distributed in a large region between 100 and 250. From the statistical analysis of Figure 16 for the turbulence integral scales both in longitudinal (Figure 16(a)) and lateral (Figure 16(b)) directions, where $R_{i_{1} i_{2}}(x)$ is the covariance function of fluctuating components in two positions.

In general, spatial correlation needs to be transferred into time correlation by Taylor hypothesis due to the fact that simultaneously measuring recorded points in space are complex and difficult. Thus, turbulence integral scale can (b) Lateral and vertical directions, respectively. Turbulence integral scale $L_{i}^{x}$ is mathematically defined as

$$
L_{i}^{x}=\frac{1}{\sigma_{i}^{2}} \int_{0}^{\infty} R_{i_{1} i_{2}}(x) d x, \quad i=u, v, w
$$




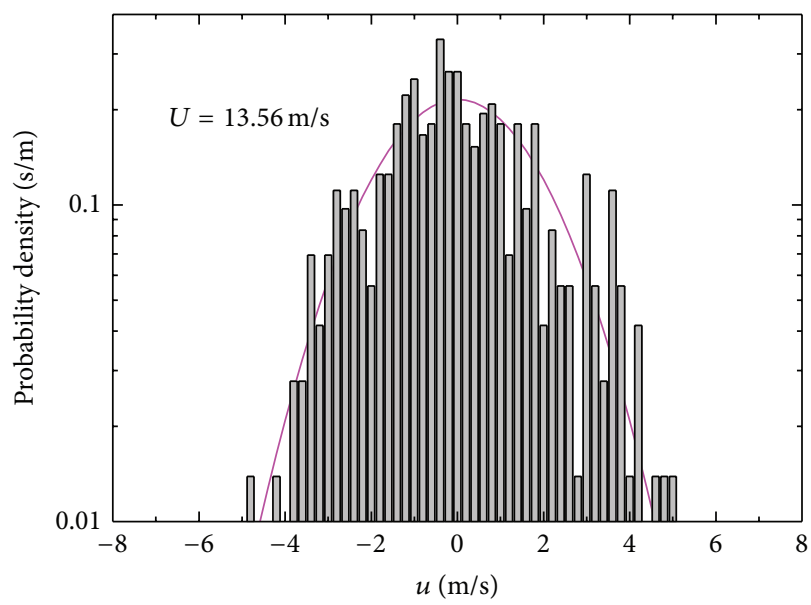

Measured Gaussian

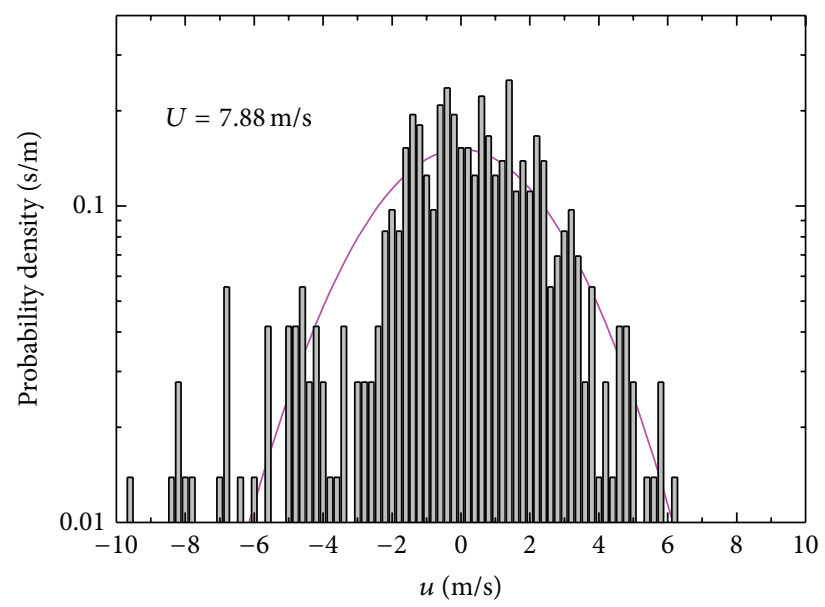

Measured

Gaussian

(a)

(b)

FIGURE 13: Probability density function of longitudinal wind speed fluctuations.

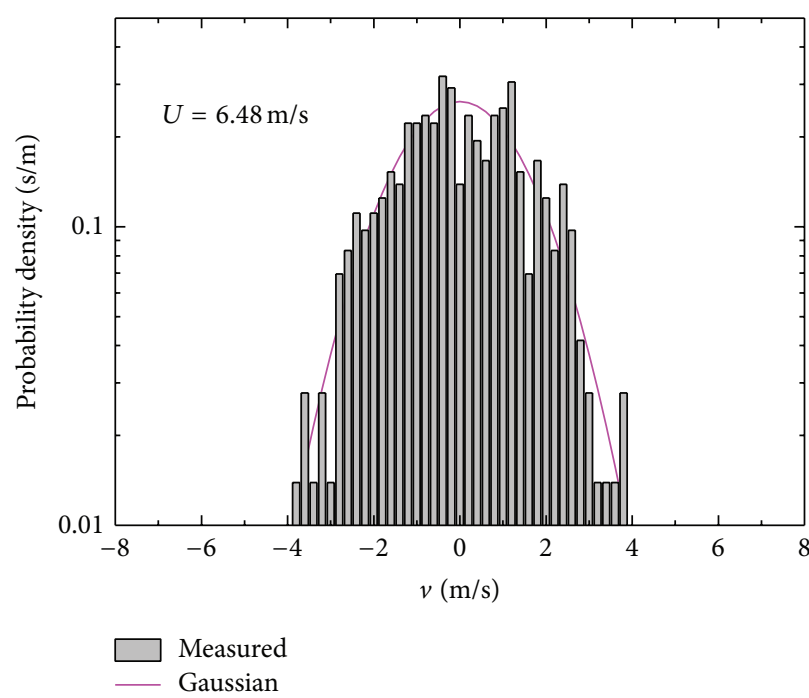

(a)

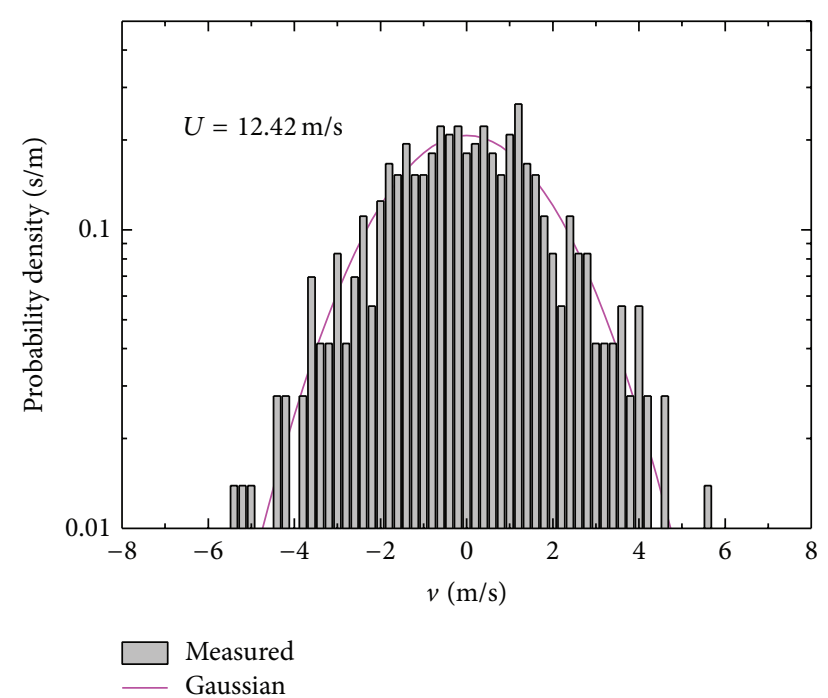

(b)

FIGURE 14: Probability density function of lateral wind speed fluctuations.

a similarity of probability density distribution is observed in each component; as it is obviously asymmetrical and differs from a standardized Gaussian distribution, in particular at low turbulence integral scales which is between 20 and 40 , the probability is the largest with most data locate in this region.

3.7. Correlation. Autocorrelation describes the correlation of two dependent values of a time series at different moments. $X(t)$ is here defined as a time series, and the correlation function can be derived as

$$
R_{X X}\left(t_{1}, t_{2}\right)=E\left[X\left(t_{1}\right) X\left(t_{2}\right)\right]
$$

Whereas $X(t)$ denotes a stationary random process, the correlation function can be derived as

$$
R_{X X}(\tau)=E[X(t) X(t+\tau)],
$$

where $R_{X X}$ is the autocorrelation function and $\tau$ is the delaying time.

Indicating correlation intensity of wind speed fluctuations for different directions, cross-correlation coefficient can be expressed as

$$
C_{R(i j)}=\frac{R_{i j}(0)}{\sqrt{R_{i i}(0)} \sqrt{R_{j j}(0)}},
$$




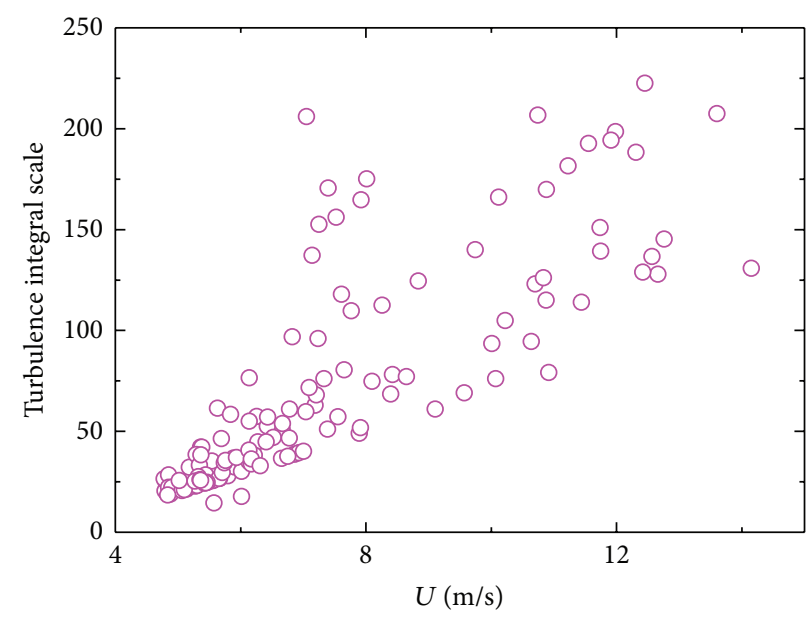

○ Longitudinal

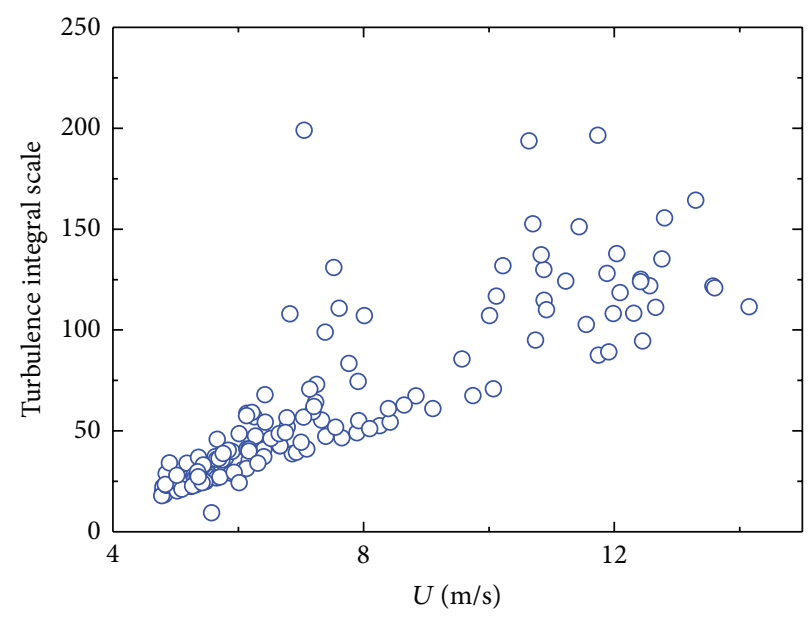

○ Lateral

(a) Longitudinal

(b) Lateral

FIGURE 15: Variation of turbulence integral scale with 10 min mean wind speed.

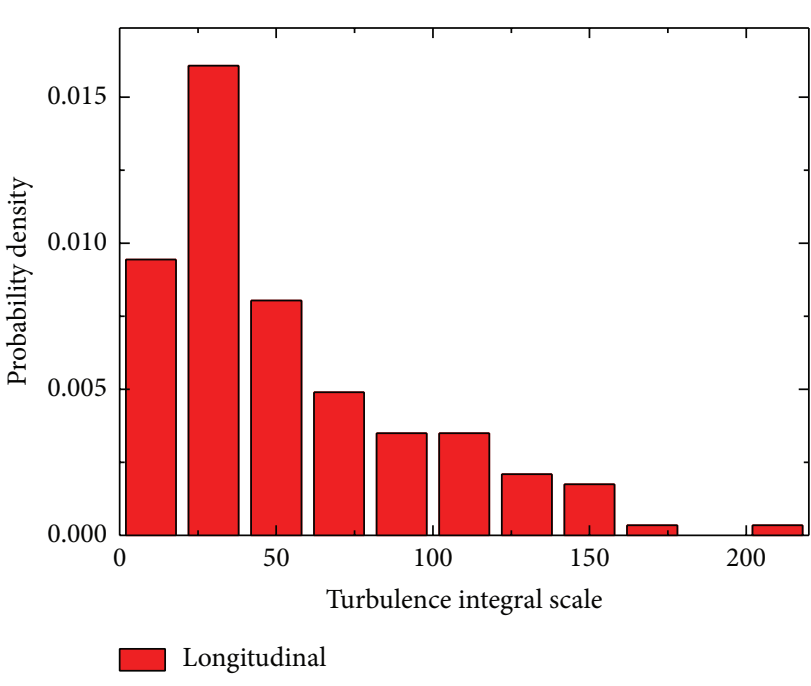

(a) Longitudinal

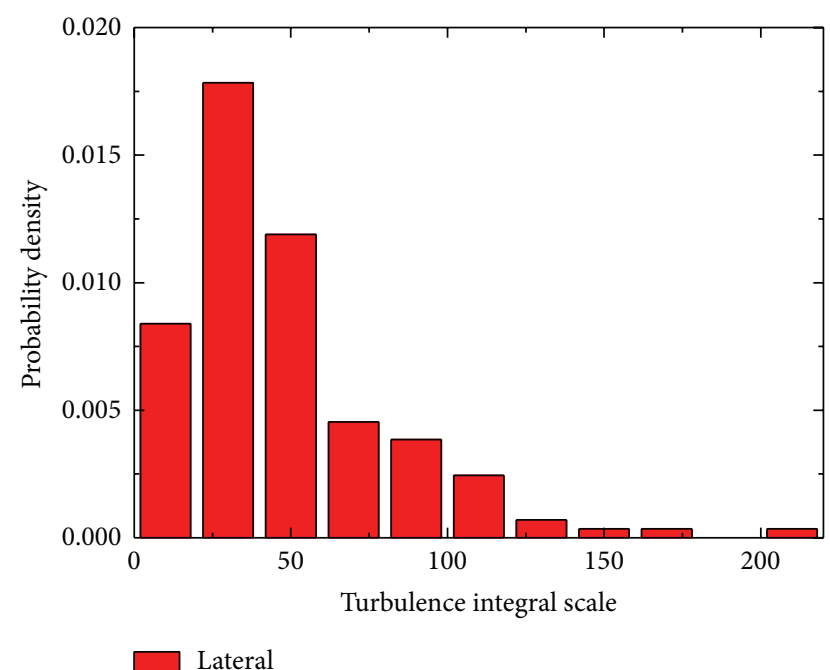

(b) Lateral

FIGURE 16: Probability density function of turbulence integral scale.

where $C_{R(i j)}$ is cross-correlation coefficient of wind speed fluctuations in $i$ and $j$ directions, $R_{i j}$ is cross-correlation function of wind speed fluctuations in $i$ and $j$ directions, and $R_{i i}$ and $R_{j j}$ are autocorrelation functions of wind speed fluctuations in $i$ and $j$ directions, respectively.

The autocorrelation coefficients for both longitudinal and lateral wind speed fluctuations are plotted in Figure 17 at the average level of $10 \mathrm{~min}$ time interval. It is found that a noticeable similarity of tendency is observed from the two plots; in particular with $\tau$ increases, the autocorrelation coefficients for both directions decrease, whereas the longitudinal autocorrelation coefficient is shown slightly larger than the lateral autocorrelation coefficient at the same delaying time $\tau$.
3.8. Power Spectra of Wind Speed Fluctuations. Turbulent power spectrum is a describer of turbulent energy distribution in frequency domain and characteristics of wind fluctuation. It can be expressed as [28]

$$
\frac{S_{u}(n, z)}{U_{0}^{* 2}}=\frac{A}{\left(1+B f^{\beta}\right)^{\gamma}},
$$

where $n$ is frequency; $z$ is the observed height; $f$ denotes reduced frequency derived as $f=n z / U(z)$; and $A, B, \beta$, and $\gamma$ are undetermined parameters.

Functions of power spectra densities of wind speed fluctuations were expressed in accordance with the Kolmogorov principle as Davenport spectrum, Von Karman spectrum, Simiu spectrum, Kaimal spectrum, and Harris spectrum. 


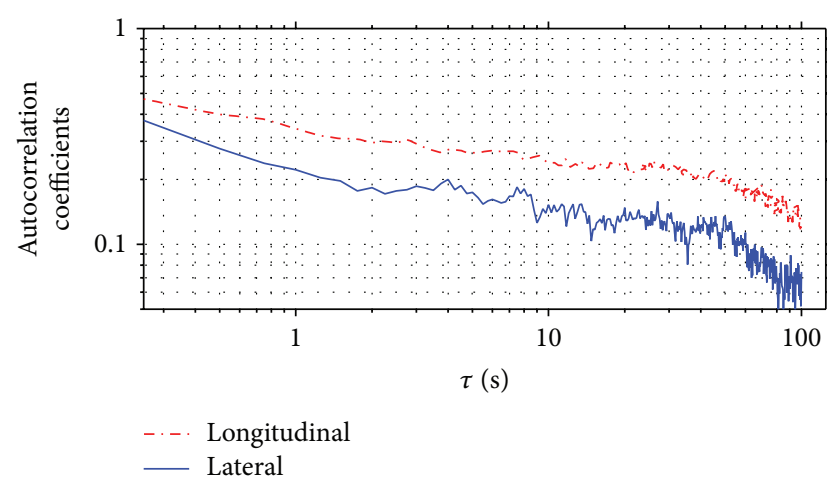

FIGURE 17: Autocorrelation coefficients of longitudinal and lateral wind speed fluctuation component.

Based on the comparisons with field measurement and wind tunnel test, Von Karman spectrum is believed as the best fitted function for wind speed fluctuations. The longitudinal fluctuating component can be expressed as $[25,29]$

$$
S_{u}(n)=\frac{2 \overline{u^{\prime 2}} L_{u}^{x}}{\bar{U}\left[1+\left(2 c n L_{u}^{x} / \bar{U}\right)^{2}\right]^{5 / 6}},
$$

where $\bar{U}$ is mean wind speed; $L_{x}^{u}$ is longitudinal turbulence integral scale; $\overline{u^{\prime 2}}$ is standard deviation of the longitudinal fluctuating component; and constant coefficient $c$ is 4.2065.

Power spectral densities of the longitudinal and lateral fluctuating components are derived from the same characteristic of turbulence hypothesis:

$$
S_{v}(n)=S_{w}(n)=\frac{1}{2}\left[S_{u}(n)-\frac{n d S_{u}(n)}{d n}\right] .
$$

For isotropic turbulences, $\overline{v^{\prime 2}}=\overline{w^{\prime 2}}=\overline{u^{\prime 2}}, L_{u}^{x}=L_{v}^{y}=L_{w}^{z}$, some equations are obtained from plugging (12) into (13):

$$
\begin{gathered}
S_{v}(n)=\frac{\overline{v^{\prime 2}} L_{v}^{y}\left[1+(8 / 3)\left(c n L_{v}^{y} / \bar{U}\right)^{2}\right]}{\bar{U}\left[1+\left(2 c n L_{v}^{y} / \bar{U}\right)^{2}\right]^{11 / 6}}, \\
S_{w}(n)=\frac{\overline{w^{\prime 2}} L_{w}^{z}\left[1+(8 / 3)\left(c n L_{w}^{z} / \bar{U}\right)^{2}\right]}{\bar{U}\left[1+\left(2 c n L_{w}^{z} / \bar{U}\right)^{2}\right]^{11 / 6}} .
\end{gathered}
$$

If $L_{v}^{x}=L_{w}^{x}=0.5 L_{u}^{x}$ for isotropic turbulences, the expressions of Von Karman spectrum are derived from plugging $L_{v}^{x}=L_{w}^{x}=0.5 L_{u}^{x}$ into (14):

$$
\begin{gathered}
\frac{n S_{u}(n)}{\sigma_{u}^{2}}=\frac{4 f}{\left(1+70.8 f^{2}\right)^{5 / 6}}, \\
\frac{n S_{i}(n)}{\sigma_{i}^{2}}=\frac{4 f\left(1+755.2 f^{2}\right)}{\left(1+283.2 f^{2}\right)^{11 / 6}}, \quad i=v, w .
\end{gathered}
$$

In Figures 18 and 19, field-measured power spectral densities of longitudinal and lateral fluctuate components are shown at wind speed of $13.56 \mathrm{~m} / \mathrm{s}$ and $7.88 \mathrm{~m} / \mathrm{s}$, presenting a good agreement with the Karman empirical spectra for the whole set of data. However, the PSD data estimated by field measurement are slightly larger than that by empirical method when the reduced frequency $n z / U(z)$ is smaller than 0.1 or larger than 0.1 .

\section{Conclusions}

Through a full-scale wind speed and direction monitoring system on Jiubao Bridge in Hangzhou city, this paper presents a reliable study of wind speed and direction characteristics during typhoon HAIKUI, such as time histories of mean wind speed and direction, turbulence intensity, peak factor, gust factor, probability distribution of fluctuating velocity component, correlation among fluctuating velocities, turbulence integral scale, and the power spectrum of fluctuating velocity, and the results are summarized as follows.

(1) Turbulence intensities decrease with increased anemometer elevation for both longitudinal and lateral components of mean wind speed. A remarkable decrease of turbulence intensity is shown with increased mean wind speed, typically at low mean wind speeds $(u<8 \mathrm{~m} / \mathrm{s})$, but an unknown tendency when mean wind speed exceeds $8 \mathrm{~m} / \mathrm{s}$. The ratio of turbulence intensities of longitudinal component to lateral component is 0.85 in this paper, indicating a clear similarity with the results by Tieleman, Cao, and Bao-Shi, whereas a certain deviation from Huang et al's results [11].

(2) Gust factors decrease with mean wind speed. An obvious decrease of the change rate is found at low wind speeds, but wind speed seems to have less impact on the change rate when it becomes high. The average ratio for gust factor of longitudinal component to lateral component is 0.30 . The upper and lower peak factors are recorded as 0.6 and 2.5; the average and standard deviation are 1.52 and 0.34 , respectively. A noticeable decrease is found from the analysis of the average peak factor compared with Peng et al's results [12].

(3) Probability density distribution of wind speed fluctuations at different wind speeds agrees well with a Gaussian distribution, which means the fullmeasured recorded data of wind speed fluctuations are in accordance with Gauss assumption.

(4) Increasing quantity of turbulence integral scales is recorded by increased $10 \mathrm{~min}$ mean wind speed. $\mathrm{A}$ similarity of probability distributions of turbulence integral scales of the three components is that each distribution is obviously asymmetrical and does not follow a standardized Gaussian distribution.

(5) Power spectral densities of recorded wind speed fluctuations are fairly good in agreement with Von Karman spectrum. 


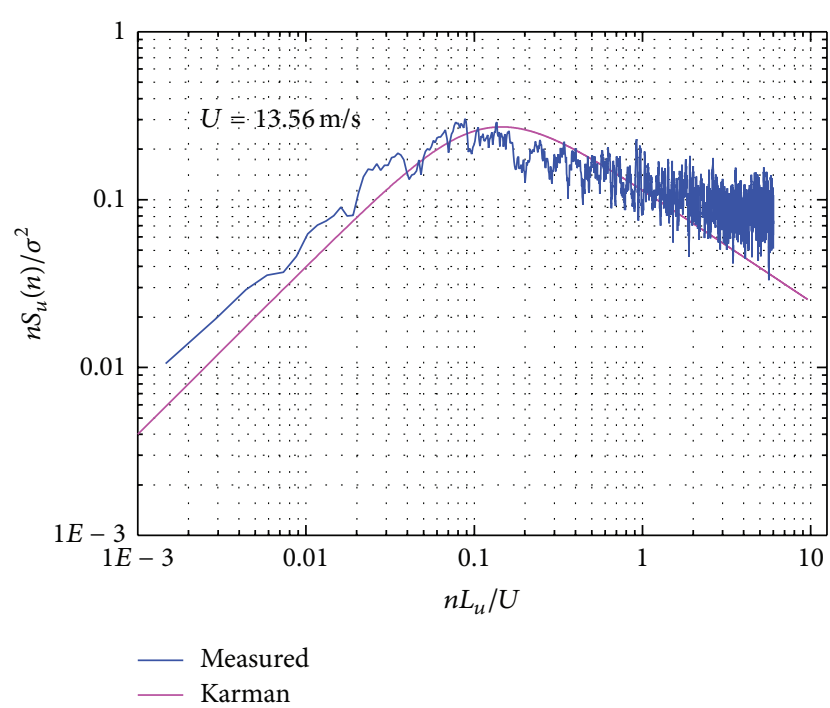

(a) Longitudinal

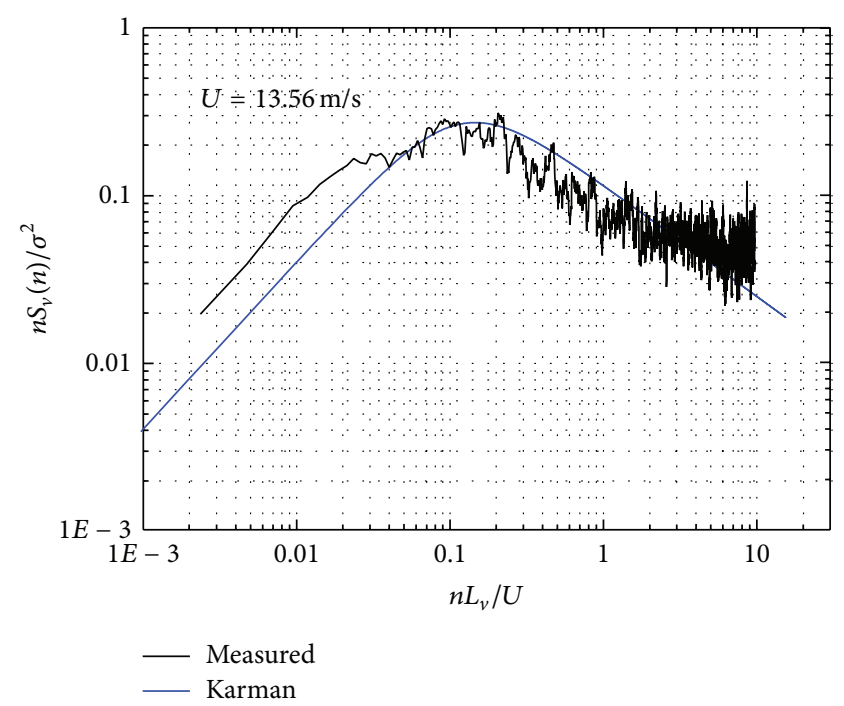

(b) Lateral

FIgURE 18: Power spectral density of fluctuation wind speed components $(U=13.56 \mathrm{~m} / \mathrm{s})$.

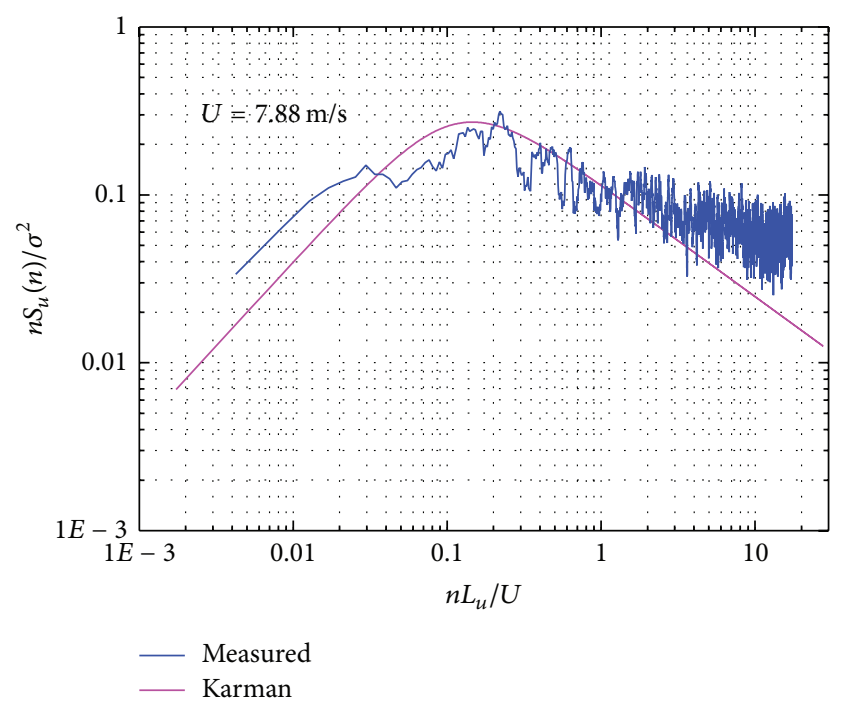

(a) Longitudinal

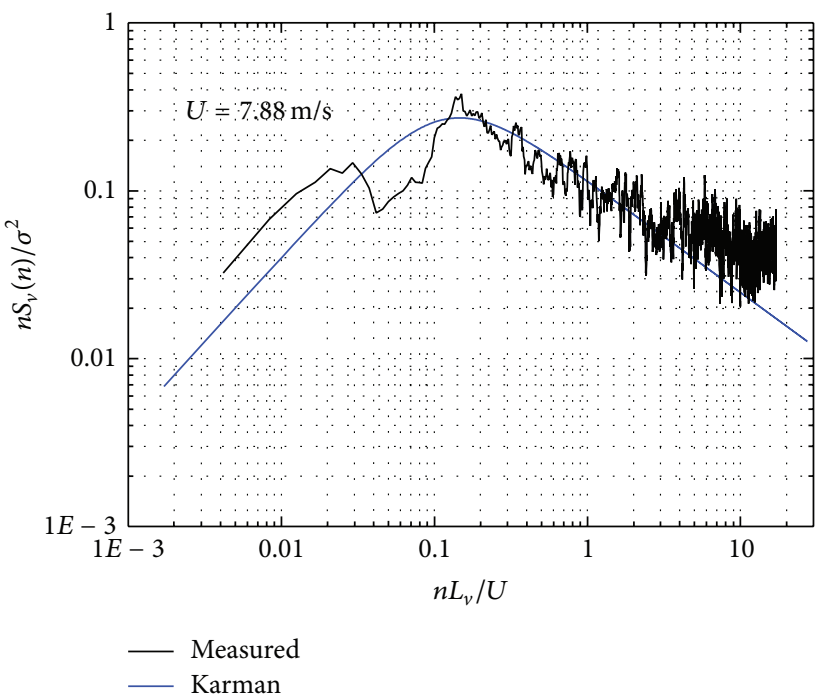

(b) Lateral

FIGURE 19: Power spectral density of fluctuation wind speed components $(U=7.88 \mathrm{~m} / \mathrm{s})$.

\section{Conflict of Interests}

The authors declare that there is no conflict of interests regarding the publication of this paper.

\section{Acknowledgments}

This project is supported by Open Fund of State Key Laboratory Breeding Base of Mountain Bridge and Tunnel Engineering (CQSLBF-Y14-15), the National Program on Key Basic Research Project (973 Program) Grant no. 2012CB723305, the Chinese National Natural Science Foundation (51308510), and Zhejiang Provincial Natural Science
Foundation (Q12E080026) which are gratefully acknowledged.

\section{References}

[1] M. Gu, The Research Process and Basic Scientific Issues about Civil Structure, Science Press, Beijing, China, 2006.

[2] C. S. Durst, "Wind speeds over short periods of time," The Meteorological Magazine, vol. 89, pp. 181-186, 1960.

[3] N. Kato, T. Ohkuma, J. R. Kim, H. Marukawa, and Y. Niihori, "Full scale measurements of wind velocity in two urban areas using an ultrasonic anemometer," Journal of Wind Engineering and Industrial Aerodynamics, vol. 41, no. 1-3, pp. 67-78, 1992. 
[4] R. G. J. Flay and D. C. Stevenson, "Integral length scales in strong winds below $20 \mathrm{~m}$," Journal of Wind Engineering and Industrial Aerodynamics, vol. 28, no. 1-3, pp. 21-30, 1988.

[5] E. C. C. Choi and F. A. Hidayat, "Gust factors for thunderstorm and non-thunderstorm winds," Journal of Wind Engineering and Industrial Aerodynamics, vol. 90, no. 12-15, pp. 1683-1696, 2002.

[6] S. Y. Cao, Y. Tamura, N. Kikuchi, M. Saito, I. Nakayama, and Y. Matsuzaki, "Wind characteristics of a strong typhoon," Journal of Wind Engineering and Industrial Aerodynamics, vol. 97, no. 1, pp. 11-21, 2009.

[7] Q. S. Li, Y. Q. Xiao, J. Y. Fu, and Z. N. Li, "Full-scale measurements of wind effects on the Jin Mao building," Journal of Wind Engineering and Industrial Aerodynamics, vol. 95, no. 6, pp. 445-466, 2007.

[8] Q. S. Li, Y. Q. Xiao, and C. K. Wong, "Full-scale monitoring of typhoon effects on super tall buildings," Journal of Fluids and Structures, vol. 20, no. 5, pp. 697-717, 2005.

[9] Q. S. Li, Y. Q. Xiao, C. K. Wong, and A. P. Jeary, "Field measurements of typhoon effects on a super tall building," Engineering Structures, vol. 26, no. 2, pp. 233-244, 2004.

[10] Q. S. Li, L. Zhi, and F. Hu, "Boundary layer wind structure from observations on a $325 \mathrm{~m}$ tower," Journal of Wind Engineering and Industrial Aerodynamics, vol. 98, no. 12, pp. 818-832, 2010.

[11] P. Huang, X. Wang, and M. Gu, "Field experiments for wind loads on a low-rise building with adjustable pitch," International Journal of Distributed Sensor Networks, vol. 2012, Article ID 451879, 10 pages, 2012.

[12] H. Peng, X. Wang, and M. Gu, "Study on near-ground wind characteristics of a strong typhoon-wind speed, turbulence intensities, gust factors and peak factors," Disaster Advances, vol. 6, no. 5, pp. 3-18, 2013.

[13] T. H. Yi, H. N. Li, and M. Gu, "Recent research and applications of GPS based technology for bridge health monitoring," Science China Technological Sciences, vol. 53, no. 10, pp. 2597-2610, 2010.

[14] T.-H. Yi, H.-N. Li, and M. Gu, "Optimal sensor placement for structural health monitoring based on multiple optimization strategies," The Structural Design of Tall and Special Buildings, vol. 20, no. 7, pp. 881-900, 2011.

[15] T.-H. Yi, H.-N. Li, and M. Gu, "Wavelet based multi-step filtering method for bridge health monitoring using GPS and accelerometer," Smart Structures and Systems, vol. 11, no. 4, pp. 331-348, 2013.

[16] T.-H. Yi, H.-N. Li, and M. Gu, "Experimental assessment of high-rate GPS receivers for deformation monitoring of bridge," Journal of the International Measurement Confederation, vol. 46, no. 1, pp. 420-432, 2013.

[17] American Society of Civil Engineers, ASCE/SEI 7-10 Minimum Design Loads for Buildings and Other Structures, American Society of Civil Engineers, Reston, Va, USA, 2010.

[18] Department of Civil Engineering Indian Institute of Technology Roorkee, IS:875(Part3): Wind Loads on Buildings and Structures-Proposed Draft \& Commentary, Indian Institute of Technology, Roorkee, India, 2003.

[19] Architectural Institute of Japan, AIJ 2004 Recommendations for Loads on Buildings, Architectural Institute of Japan, Tokyo, Japan, 2004.

[20] Technical Committee CEN/TC250 "Structural Eurocodes", Eurocode 1: Actions on Structures-General Actions-Part 1-4: Wind Actions, British Standards Institution, London, UK, 2004.

[21] GB50009-2001, Load Code for the Design of Building Structures, Architecture and Building Press, Beijing, China, 2002.
[22] E. Simiu and R. H. Scanlan, Wind Effects on Structures: Fundamentals and Applications to Design, John Wiley \& Sons, New York, NY, USA, 1996.

[23] J. Y. Fu, Q. S. Li, J. R. Wu, Y. Q. Xiao, and L. L. Song, "Field measurements of boundary layer wind characteristics and wind-induced responses of super-tall buildings," Journal of Wind Engineering and Industrial Aerodynamics, vol. 96, no. 8-9, pp. 1332-1358, 2008.

[24] B.-S. Shiau, "Velocity spectra and turbulence statistics at the northeastern coast of Taiwan under high-wind conditions," Journal of Wind Engineering and Industrial Aerodynamics, vol. 88, no. 2-3, pp. 139-151, 2000.

[25] B.-S. Shiau and Y.-B. Chen, "In situ measurement of strong wind velocity spectra and wind characteristics at Keelung coastal area of Taiwan," Atmospheric Research, vol. 57, no. 3, pp. 171-185, 2001.

[26] B.-S. Shiau and Y.-B. Chen, "Observation on wind turbulence characteristics and velocity spectra near the ground at the coastal region," Journal of Wind Engineering and Industrial Aerodynamics, vol. 90, no. 12-15, pp. 1671-1681, 2002.

[27] H. W. Tieleman, "Strong wind observations in the atmospheric surface layer," Journal of Wind Engineering and Industrial Aerodynamics, vol. 96, no. 1, pp. 41-77, 2008.

[28] P. J. Richards, R. P. Hoxey, and J. L. Short, "Spectral models for the neutral atmospheric surface layer," Journal of Wind Engineering and Industrial Aerodynamics, vol. 87, no. 2-3, pp. 167-185, 2000.

[29] T. Karman, "Progress in the statistical theory of turbulence," Proceedings of the National Academy of Sciences, vol. 34, pp. 530539, 1948. 

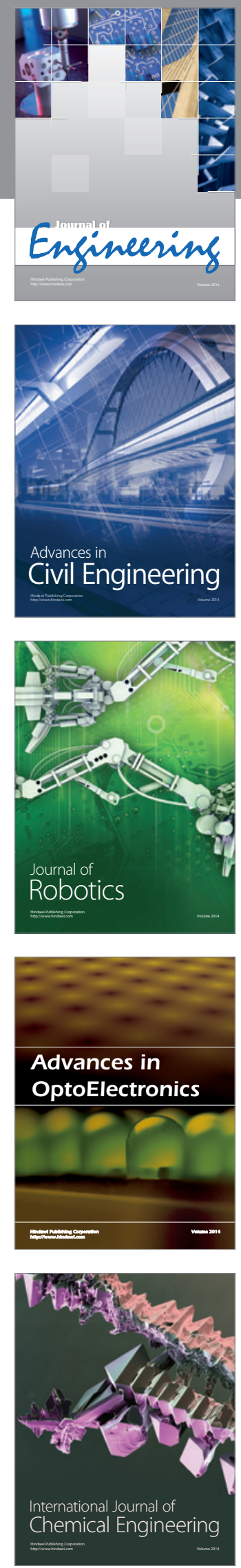

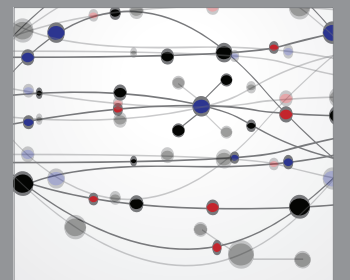

The Scientific World Journal
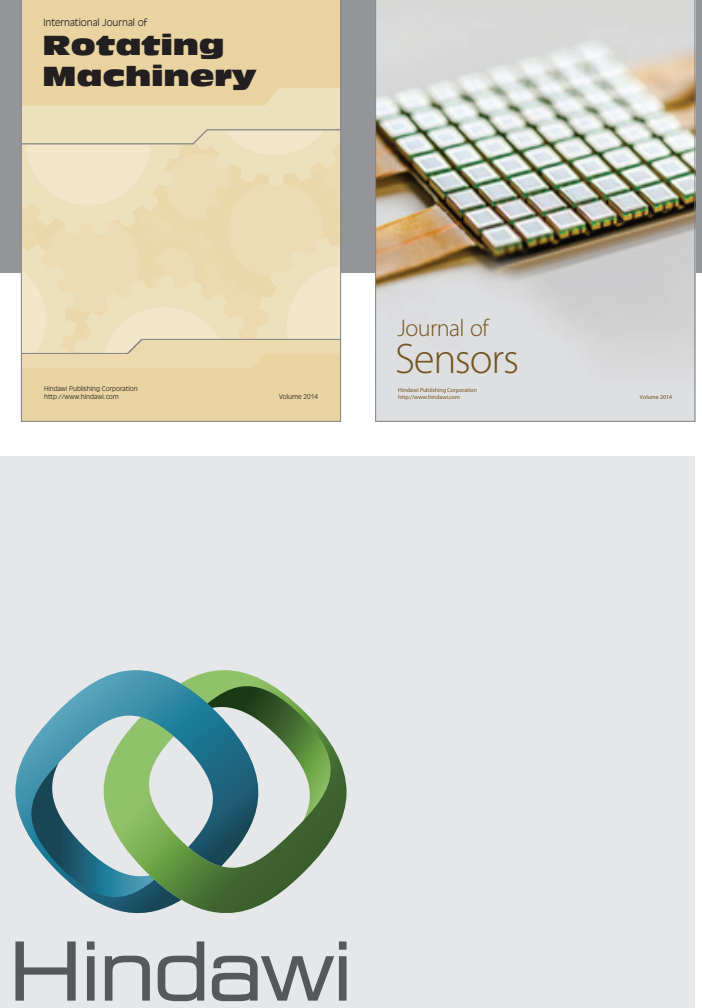

Submit your manuscripts at http://www.hindawi.com
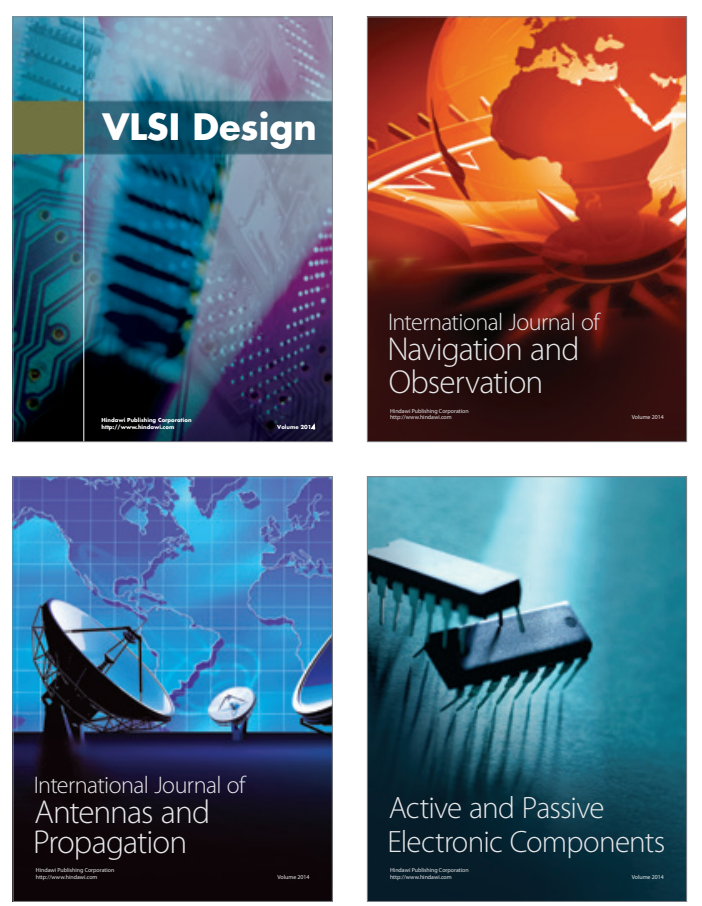
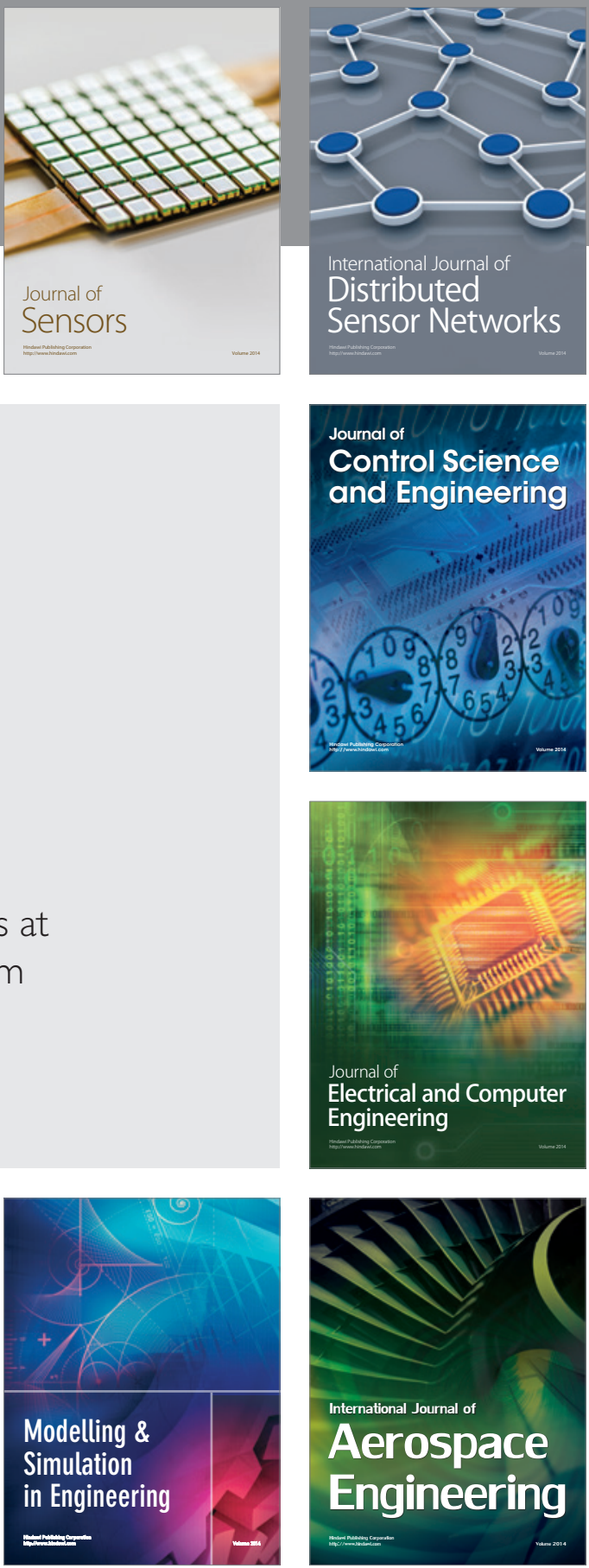

Journal of

Control Science

and Engineering
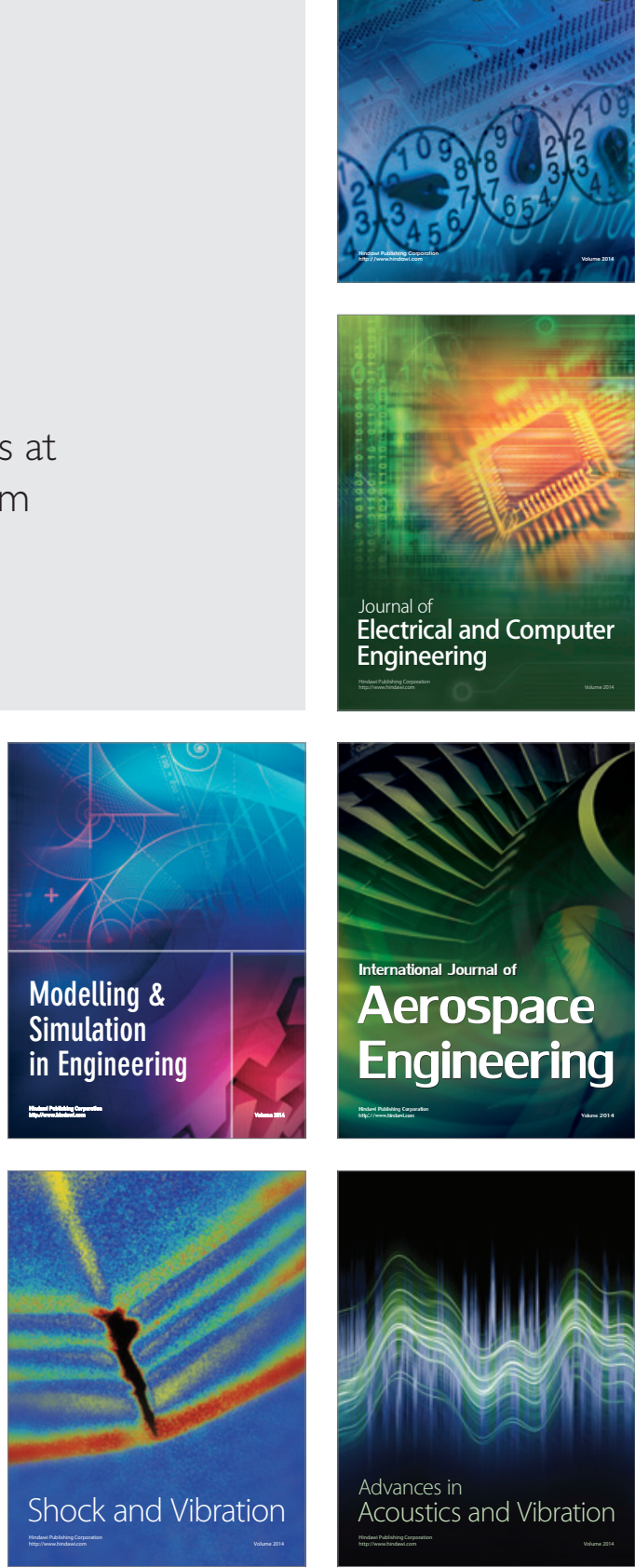